\title{
Erratum to: Developing Novel Approaches to Tracking Domestic Water Demand Under Uncertainty-A Reflection on the "Up Scaling" of Social Science Approaches in the United Kingdom
}

\author{
Alison L. Browne • Will Medd • Ben Anderson
}

Published online: 27 November 2012

(C) Springer Science+Business Media Dordrecht 2012

\section{Erratum to: Water Resour Manage \\ DOI 10.1007/s11269-012-0117-y}

The original version of this article unfortunately contained a mistake in Fig. 1. The presentation of Fig. 1 was incorrect. The updated Fig. 1 is given below.

The online version of the original article can be found at http://dx.doi.org/10.1007/s11269-012-0117-y.

A. L. Browne $(\bowtie) \cdot$ W. Medd

Lancaster Environment Centre, Lancaster University, Lancaster, UK LA1 4YQ

e-mail: a.browne@lancaster.ac.uk

W. Medd

e-mail: w.medd@lancaster.ac.uk

B. Anderson

Centre for Research in Economic Sociology and Innovation, Essex University, Essex, UK 


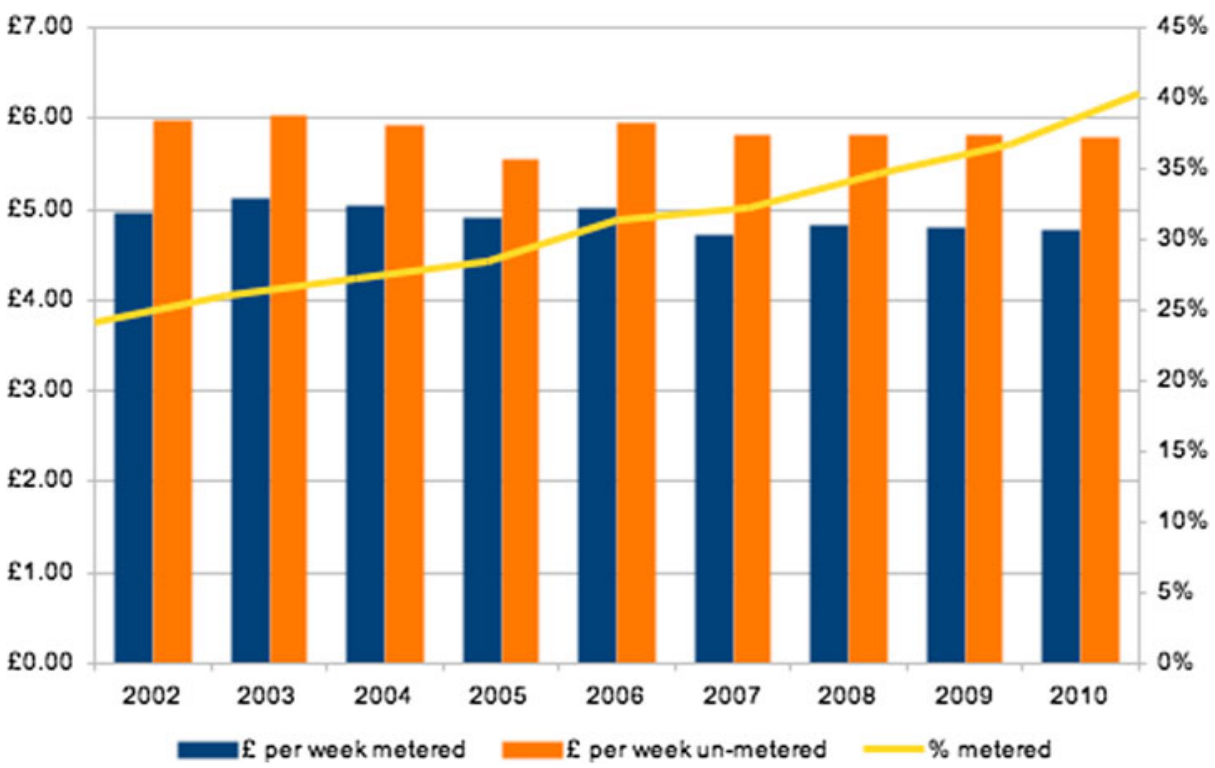

Fig. 1 Trends in mean household water expenditures for metered and unmetered households and overall metering rate, England (LC\&F Survey 2002-2010, mean weekly expenditure (£, 2005 water prices), \% metered of all those who pay own water bill, weighted, authors' calculations) 